\title{
Aspectos de sustentabilidade no segmento de petróleo na cidade de Mossoró-RN.
}

Sustainability issues following oil city in mossoro-rn.

\author{
Cacilda Alves de Sousa; Sandra Maria Campos Alves; Carlos Enrique de M. Jerônimo \\ I Mestranda em Engenharia de Petróleo e Gás pela Universidade Potiguar em Mossoró- RN. \\ Professora PhD da Universidade Potiguar em Mossoró - RN - Brasil \\ Professor Doutor da Universidade Potiguar - RN
}

\begin{abstract}
Resumo
A conjuntura econômica requer das organizações uma nova atitude, onde possam incluir em suas atividades a elaboração de demonstrações abrangendo não somente o aspecto econômico, mas um maior comprometimento no que diz respeito às ações humanas, sociais e ambientais. Por isso, o presente trabalho tem como objetivo verificar se os relatórios socioambientais de uma empresa petrolífera localizada na cidade de Mossoró-RN auxiliam na elaboração do seu Balanço Social. A partir de uma análise realizada nas informações contidas nos relatórios socioambientais disponíveis no site da organização estudada, procura-se através desta investigação, comparar à luz da pesquisa científica, se as informações registradas nos relatórios socioambientais contribuem para a elaboração de um balanço social, auxiliando na disseminação da importância dos registros contábeis evidenciarem de forma transparente as ações socioambientais da organização. Os resultados obtidos apontaram que as ações de responsabilidade socioambientais desenvolvidas pela empresa que atua no ramo de petróleo, poderão ser utilizadas para a elaboração do Balanço Social tanto no modelo GRI (Global Reporting Iniciative) bem como também no modelo IBASE. Percebe-se que a empresa mostra uma nova fase do capitalismo que está explorando uma vertente social como maneira de justificar o lucro obtido com a exploração do meio ambiente que socialmente pertence a todos.
\end{abstract}

Palavras-chave: Balanço Social. Responsabilidade Social. Relatórios Socioambientais.

\begin{abstract}
The economic environment of organizations requires a new attitude, which may include in its activities the preparation of financial statements covering not only the economic aspect, but a greater commitment with respect to human actions, social and environmental. Therefore, this study aims to determine whether the social and environmental reports of an oil company located in Mossoro-RN assists in the preparation of its Social. From an analysis of the information in social and environmental reports available on the website of the organization studied, looking up through this research, compare the light of scientific research, the information recorded in the social and environmental reports contribute to the development of a social, helping dissemination of the importance of accounting records evidencing a transparent manner environmental actions of the organization. The results showed that the social and environmental responsibility actions developed by the company that operates in the field of oil, may be used for the preparation of both Social GRI (Global Reporting Initiative) and also in the model IBASE. It is noticed that the company shows a new phase of capitalism that is exploring a social as a way to justify the profit on the operation of the social environment that belongs to everyone.
\end{abstract}

Keywords: Social balance sheet. Social Responsibility. Social and Environmental Reports. 


\section{INTRODUÇÃO}

Em virtude das mudanças econômicas, em um cenário cada vez mais globalizado, onde clientes e investidores estão mais exigentes, é visível e crescente a conscientização e preocupação da sociedade em adquirir produtos e serviços de empresas socialmente responsáveis. A atual conjuntura econômica requer das organizações uma nova postura, onde possam incluir em suas atividades a elaboração de demonstrações abrangendo não somente o aspecto econômico, mas um maior comprometimento no que diz respeito às ações humanas, sociais e ambientais.

O Balanço Social apresenta-se como ferramenta facilitadora para transparecer essas ações e demonstrar o nível de comprometimento das empresas com as causas socioambientais. A transparência das informações divulgadas através dessa ferramenta pode agregar valor à organização, aumentando a confiabilidade e credibilidade dos produtos e serviços deixando-a em vantagem em relação aos seus concorrentes.

Deverá constar na demonstração da empresa toda política voltada para o desenvolvimento, aprimoramento e crescimento de seus colaboradores, sejam eles funcionários, fornecedores, consumidores, entre outros, bem como todos os projetos que envolvam as ações voltadas para melhorias da qualidade de vida da comunidade, como, manutenções do meio ambiente, contribuições junto a entidades filantrópicas, e outras.

Em virtude da preocupação acima referenciada, a pesquisa tem a intenção de levantar a seguinte problemática: as ações de responsabilidade socioambientais desenvolvidas pela empresa que atua do ramo de petróleo localizada em Mossoró $\mathrm{RN}$ são registradas em relatórios socioambientais? E esses relatórios socioambientais contribuem para a composição de um Balanço Social? Acredita-se que as informações geradas a partir dos relatórios socioambientais possibilitarão a elaboração de um Balanço Social, uma vez que, tendem a evidenciar a transparência e preocupação da organização com o meio ambiente e com a sociedade, bem como agregar valor ao negócio.

O objetivo geral dessa pesquisa está baseado em verificar se os relatórios socioambientais da referida empresa auxiliam na elaboração do Balanço Social e tem como objetivo específico identificar se os tipos de relatórios que são gerados e publicados por essa empresa, evidenciam ações socioambientais, e averiguar através dos modelos de balanços estudados qual será o mais viável para demonstrar as ações socioambientais dessa empresa.

Nessa pesquisa serão abordados aspectos relacionados às ações socioambientais, onde será identificada a importância das indústrias evidenciar suas ações de responsabilidade social, deixando explícita a transparência das melhores práticas para o desenvolvimento sustentável e funcional da organização, cuidados com o meio ambiente e benfeitorias para a comunidade onde está inserida.

\section{REFERENCIAL TEÓRICO}

\section{I Histórico do Balanço Social}

Os primeiros indícios do Balanço Social se deram nos Estados Unidos da América a partir das consequências oriundas da Guerra do Vietnã nas décadas de 60 e 70 . Consequências estas que trouxeram sofrimento e morte à população, acarretando inúmeros danos à sociedade e ao meio ambiente. $\mathrm{O}$ fato provocou indignação e revolta do povo em relação às empresas envolvidas no conflito, fazendo com que fosse adotada uma nova postura moral e ética das organizações perante a sociedade.

Diante do exposto, surge a preocupação das empresas em apresentarem os primeiros relatórios socioeconômicos que procuravam descrever suas ações sociais. Porém foi na Europa, mais especificamente na França na década de 70 a partir da divulgação do primeiro Balanço Social da empresa Singer e em conseguinte com a promulgação da Lei $\mathrm{n}^{\circ} 77.769$ de 12 de Julho de 1977 que o Balanço Social teve maior aceitação, onde obrigava as entidades que possuíam mais de 700 funcionários a publicá-1o, o que posteriormente reduziu para 300 funcionários. Em pouco tempo vários países europeus aderiram a Lei francesa e passaram a publicar também o balanço social, destacando entre eles, Alemanha, Holanda, Bélgica, Espanha, Portugal e Inglaterra. No entanto há obrigatoriedade para alguns desses países, nos demais sua divulgação é resultado das pressões sociais (TINOCO, 2002).

No Brasil os primeiros pensamentos relacionados a ações sociais foram influenciados pela ADCE (Associação dos Dirigentes Cristãos de Empresas) na década de 60 que defendia a responsabilidade social das organizações. No entanto, o primeiro documento de informações sociais divulgado no Brasil denominado de Balanço Social foi publicado voluntariamente em 1984 através da empresa Nitrofértil na cidade de Camaçari estado 
da Bahia. E ainda em meados da década de 80 foi publicado o da Telebrás, e o da Banespa em 1992, formando o rol das empresas precursoras do Balanço Social no Brasil.

A partir dos manifestos do sociólogo Herbert de Souza (Betinho), em conjunto com o Instituto Brasileiro de Análises Sociais e Econômicas (IBASE), e apoiado por lideranças empresariais, foi dado uma maior ênfase ao Balanço Social, retomando discussões sobre o tema e levando empresas de diferentes setores a começarem a elaborar seus documentos de divulgação das ações de cunho socioambiental para a sociedade (TORRES, 2007).

\subsection{Conceitos do Balanço Social}

O Balanço Social vem se destacando nas últimas décadas em virtude da cobrança da sociedade em tornar as informações socioambientais cada vez mais transparentes e acessíveis. Com o intuito de minimizar os preconceitos e injustiças existentes, passa a ser exigido das organizações compromisso e envolvimento com o meio ambiente e com a sociedade, sendo estes, uma forma de contribuição que proporciona resultados e benefícios mútuos.

$\mathrm{Na}$ busca de um conceito que possa fundamentar a utilização do Balanço Social, entende-se que o mesmo é o resultado de pressões sociais que visam aperfeiçoar a transparência das informações e as políticas praticadas pelas entidades em benefício da comunidade. Ressalta-se ainda que o Balanço Social represente a demonstração dos recursos e das influências tidas como favoráveis, quando gera empregos, contribui para arrecadação de tributos, pratica ações de responsabilidade socioambiental, entre outras, e desfavoráveis quando provocam ações prejudiciais ao homem e ao meio ambiente, entre elas: poluição, acidentes de trabalho, ações judiciais provenientes de causas ambientais, etc. (KROETZ, 2001).

Para Tinoco (2002, p. 59), o "Balanço Social é um instrumento de gestão e de informação que visa evidenciar, da forma mais transparente possível, informações econômicas e sociais do desempenho das entidades aos mais diferenciados usuários".

O Balanço Social não se resume apenas a uma demonstração financeira, ele representa um elo entre as organizações e a sociedade, que busca alimentá-la com informações que possibilitem expressar sua responsabilidade com o social e com meio ambiente agregando valor a organização.

De acordo com Tinoco e Kramer (2008, p. 90), "o Balanço Social tem por ambição descrever certa realidade econômica, ambiental e social, de uma entidade, através do qual é suscetível de mensuração, avaliação e divulgação".

Levando-se em consideração os objetivos do Balanço Social, configuram-se alguns aspectos relevantes em relação à exposição de informações decorrentes das atividades desenvolvidas pelas organizações.

Na definição de Kroetz (2000 apud REIS; MEDEIROS, 2009, p.76), estes aspectos podem ser evidenciados através da divulgação dos indicadores humanos, econômicos e sociais, tais como: gerar investimentos na capacitação profissional de seus colaboradores envolvendo-os na gerência participativa dos processos, realizarem interação social com os stakeholders, demonstrar a contribuição da empresa com a qualidade de vida da comunidade, gerir investimentos voltados para a pesquisa e desenvolvimento tecnológico na busca da qualificação de seus produtos e serviços, construindo um diferencial de sua marca e imagem perante seus concorrentes, organizar a sistemática de procedimentos internos obedecendo às normas legais voltadas para a preocupação ambiental e explicitar seus objetivos e políticas administrativas com cautela em relação a sua divulgação para que se evidencie não somente os resultados econômicos, mas também sua contribuição no processo de avanço social.

\subsection{Aspectos Legais do Balanço Social}

As manifestações sociais vistas anteriormente culminaram para que as empresas atingidas nos conflitos divulgassem seus relatórios socioeconômicos, com o intuito de demonstrar uma maior transparência de sua responsabilidade social.

Reis e Medeiros (2009) relatam que diante desses acontecimentos, surgiu a necessidade de amparar os trabalhadores em relação a empregos, remunerações e condições de trabalhos. Na França várias experiências consolidaram a necessidade de uma avaliação mais sistemática por parte das empresas, sendo exigido das mesmas, evidenciar seus investimentos sociais, demonstrando através de um documento as medidas que haviam sido tomadas e em que amplitude.

A Singer foi à primeira empresa francesa a elaborar e divulgar em 1972 seu Balanço Social. A obrigatoriedade da elaboração e divulgação dessa demonstração aconteceu a partir da promulgação da Lei 77.769 de 12 de julho de 1977 na França, em que se tornava obrigatório a realização do Balanço Social periódico para todas as empresas e estabelecimentos que possuíssem um número 
de funcionários superior a 300 .

No entendimento de Tinoco e Kraemer (2008), essa lei estabelece sua vantagem quando reconhece pela primeira vez de forma constitucional o valor dos trabalhadores no âmbito empresarial como usuários da informação contábil e social. A lei, todavia, por seu pioneirismo na época, deixa de relacionar uma série de informações de caráter econômico e ambiental.

Enquanto isso no Brasil, nos últimos anos, vários projetos de lei foram apresentados com o intuito de legalizar a elaboração e divulgação desse relatório. Na esfera Federal, tramitou o projeto de Lei ${ }^{\circ} 3.116$ de 14 de maio de 1997 elaborado pelas Deputadas Marta Suplicy, Sandra Starling e Maria da Conceição Tavares, o qual defendia a obrigatoriedade para empresas públicas independente do número de empregados e para as privadas que possuíam mais de cem empregados no exercício anterior a sua elaboração, sendo arquivada em 1998, em virtude do término da legislatura dos seus proponentes, contudo foi reapresentado pelo projeto ${ }^{\circ} 32 / 99$ elaborado pelo deputado Paulo Rocha-PT BA.

No âmbito estadual e municipal também há uma comoção por parte dos governantes para estimular a elaboração do Balanço Social, no qual os mesmo criaram selos com o objetivo de incentivar e reconhecer as empresas que apresentarem qualidade em seu Balanço Social (TINOCO, 2008).

Na opinião de Reis e Medeiros (2009), existe uma carência no Balanço Social apresentado no Brasil, pois este está evidenciado apenas em algumas localidades, sendo na esfera Municipal somente em Porto Alegre, Santo André, São Paulo, João Pessoa, Uberlândia, na Estadual o Rio Grande do Sul e na Federal existe apenas Projetos de Lei.

Existe uma diversidade de pensamentos voltados para a regulamentação do Balanço Social no Brasil por diversos órgãos como:

A Associação Brasileira das Empresas de Capital Aberto (ABRASCA), a qual se posiciona de forma contrária ao projeto de lei que tramita atualmente no Congresso, considerando-o arcaico em relação à liberdade de escolha das empresas em divulgar ou não publicamente essa demonstração.

O Instituto Brasileiro de Análises Sociais e Econômicas (IBASE), também se posiciona de forma contrária a sua obrigatoriedade, destacando que o Balanço Social deve ser subsequente as ações sociais realizadas pelas empresas e que sua elaboração espontânea e periódica cria um circulo virtuoso, onde as organizações passariam a apresentar suas ações a partir dessa exigência, tornando crescente o número de adeptos a esta demonstração causando uma espécie de desvantagem de uns em relação aos outros.

A Comissão dos Valores Mobiliários (CVM) de início estimula a divulgação do Balanço Social quando chega a emitir o Parecer de Orientação $n^{\circ}$ 15/87 no que trata do Relatório de Administração e o Parecer de Orientação ${ }^{\circ}$ 24/92, sobre a Demonstração do Valor Adicionado (DVA). No entanto, diante das diversas manifestações ocorridas e da falta de consenso, a mesma opta por não emitir qualquer ato normativo obrigatório para a divulgação do Balanço Social.

São diversas as opiniões existentes em relação à legalização ou não do Balanço Social, onde alguns consideram que a obrigatoriedade seria bem vinda, pois estimula uma ligação harmoniosa entre a entidade e a sociedade quando deixa clara a preocupação em relação às ações sociais. Enquanto que outros criticam a obrigatoriedade acreditando que essa divulgação deve ocorrer de forma voluntária sem a necessidade de uma pressão legal, devendo ser oriunda dos preceitos éticos e morais do cidadão empresário.

\subsection{Elaboração do Balanço Social}

O Balanço Social consiste em uma ferramenta que viabiliza a comunicação entre a organização e a sociedade, serve como um meio de estimular a consciência das empresas em relação aos seus propósitos sociais.

Na visão de Perottoni (2002), é crescente o número de usuários do Balanço Social, cada um com necessidades e interesses diferentes, portanto, para atendê-los é necessária a elaboração de demonstrativos que além de observar os requisitos individuais de cada um, seja transparente, confiável e comparável, para que o mesmo agregue valor e supere as expectativas do usuário.

Tinoco (2008) acrescenta que sua elaboração comporta duas fases, uma quando o responsável promove e coordena sua concepção, ou seja, toda fase de planejamento, e uma segunda fase, que é a execução do trabalho planejado.

Reis e Medeiros (2009, p.78) enfatizam que:

O Balanço Social deve ser elaborado com o objetivo de ser uma ferramenta de diagnóstico e gestão padronizada para apresentação de indicadores de responsabilidade social, úteis a iniciativas de interesse da sociedade, tais como projetos sociais, para promoção da responsabilidade social na comunidade, nacional e global, dentre outros indica- 
dores de desempenho da gestão, como investimentos, produtividade e geração de riquezas da organização [...].

Diante das afirmações entende-se que, a elaboração do Balanço Social realizado através de informações claras e confiáveis oferece uma gama de recursos para evidenciar a responsabilidade das organizações no que se refere aos interesses sociais, inclusive de seus funcionários, comunidade e preservação do meio ambiente, deixando explícito que seus interesses não estão voltados exclusivamente paro o lado econômico, mas também para o desenvolvimento humano.

\subsection{Elementos Evidenciados no Balanço Social}

$\mathrm{Na}$ fase inicial, o Balanço Social restringia suas informações, de forma a divulgar apenas aspectos relacionados à mão de obra contratada. Com as novas perspectivas de mercado e os efeitos dos impactos sociais e ambientais oriundos do processo produtivo das entidades, desencadeou ações que destacaram o compromisso das organizações. Com isso, surgem novos elementos na estrutura de apresentação dessa demonstração, sendo estes relacionadas aos aspectos de responsabilidade social, ambiental e por fim a econômica.

O Balanço Social fornece diferentes indicadores socioeconômicos, os quais servem como instrumentos metodológicos para o estudo de processos de desenvolvimento regional, ou mesmo setorial, confrontados com parâmetros ou objetivos preestabelecidos, servindo ainda como fonte estatística das aplicações de recursos na área social e também dos recursos repassados pelas organizações ao governo, através de impostos e contribuições ali discriminados, os quais deverão ser aplicados em áreas carentes de recursos, proporcionando, assim, condições adequadas para o desenvolvimento (REIS; MEDEIROS, 2009, p.72).

Os indicadores fornecidos através do Balanço Social servem como parâmetro para medir o desempenho das organizações e a empregabilidade de seus recursos, contribuindo também para o acompanhamento, o controle e a tomada de decisão dos usuários das informações. Para Tinoco (2008), o escopo do balanço social compreende: Balanço social em sentido restrito, aos Recursos Humanos, Demonstração do Valor Adicionado, Contabilidade Ambiental e Responsabilidade social das organizações.

\subsection{Modelos de Balanço Social Aplicados no Brasil}

Os modelos de Balanço Social quando se iniciaram, realizou-se um estudo de vários modelos para chegar a uma forma de como seriam apresentadas essas informações, se seriam pelas empresas, pelo governo, pelas instituições acadêmicas ou organizações não governamentais, na busca de identificar dentro do universo de informações apresentadas, quais seriam as de maior importância para seus usuários, algumas organizações aderem a alguns dos modelos existentes, adequando-os a sua realidade ou criam o seu próprio modelo.

Na concepção de Calixto (2005), devido o Balanço Social não ter um modelo padronizado e também a falta de obrigatoriedade, leva algumas empresas a abordarem com mais ênfase os aspectos positivos dos seus investimentos sociais, sendo divulgado o que lhes convém, desviando o real sentido dessa demonstração.

No Brasil as empresas costumam adotar três modelos propostos de Balanço Social que são:

\subsection{Modelo do Instituto ETHOS \\ O modelo de Balanço Social do Instituto} ETHOS tem um foco mais voltado para a responsabilidade social, seu objetivo é apresentar informações que sejam consistentes e dignas de credibilidade. As ações divulgadas em seus relatórios demonstram o compromisso dos gestores com a sustentabilidade, o que permite atender as exigências das partes interessadas (ETHOS, 2006).

Para a elaboração do modelo de Balanço Social do Instituto ETHOS, é proposta uma planiha adaptada do modelo do IBASE, onde dentre as informações tratadas no seguimento I: a mensagem do presidente, o perfil do empreendimento e o setor da economia, no seguimento II descrevem sobre a empresa, no seguimento III contemplam os indicadores econômicos, sociais e ambientais, podendo estes ser adaptados às necessidades dos seus usuários.

\subsubsection{Modelo de Balanço Social GRI}

Quanto ao modelo do GRI (Global Reporting Iniciative ou, no português, Iniciativa Global para Apresentação de Relatórios), pode ser utilizado por organizações de qualquer porte, setor ou localidade, o indicador ambiental é o mais explorado, porém apresenta outros indicadores, os quais acabam por complementar o relatório a fim de obter um equilíbrio com a apresentação de qualidade da informação. Sua estrutura é composta 
pelo perfil da organização, formas de gestão e a abordagem dos indicadores de desempenho que são: econômico, ambiental, práticas trabalhistas e trabalho decente, direitos humanos e sociais e responsabilidade pelo produto, conforme mostra o quadro abaixo (GRI, 2006).

\subsubsection{Modelo do IBASE}

O modelo de Balanço Social do IBASE foi criado em 1997, o qual já passou por três revisões, porém seu formato não foi alterado, porque de acordo com a instituição, sua forma sucinta, não perde a comparabilidade, a simplicidade e o fácil entendimento. Apresenta em sua metodologia dados e informações de dois exercícios anuais por meio de uma tabela bastante simples e direta que deve ser publicada e amplamente divulgada (IBASE, 2007).

O modelo contempla 43 indicadores quantitativos e 8 qualitativos, organizados em sete categorias, que se divide em: a Base de cálculo, indicadores sociais internos e indicadores sociais externos (investimentos na comunidade), indicadores ambientais, indicadores do corpo funcional, indicadores organizacionais e indicadores econômicos.

\subsection{Responsabilidade Social das Organizações}

Conforme Pinto e Ribeiro (2004), as organizações para terem uma maior aceitabilidade no mercado, tem sido gradativamente condicionada ao comprometimento com o desenvolvimento econômico e sustentável da sociedade, portanto, além de agente econômico é também um agente social, e como tal, tem o dever de prestar contas a todos que interagem com ela. Em seu relacionamento com a sociedade existem obrigações implícitas, tais como: a preservação do meio ambiente, feitas através de políticas ambientais adequadas compatíveis com sua conservação, a criação e manutenção de empregos, e outras que não são exigidas por lei, mas que são esperadas de uma empresa socialmente responsável.

Para Reis e Medeiros (2009), este indicador demonstra o grau de responsabilidade social assumido pelas organizações, aprimorando suas relações de parceria, que envolve a participação em programas sociais, o gerenciamento de meios para minimizar os impactos causados a comunidade pelo desenvolvimento das operações, a erradicação do trabalho infantil, nos incentivos fiscais para a área social e cultural, está incluso também as iniciativas da empresa com o governo quando o auxilia na identificação dos setores menos beneficiado pelas políticas públicas, facilitando o direcionamento de recursos, no cumprimento de leis, objetivando a melhoria das condições de política do país, e assim prestar contas à sociedade de suas ações pelo uso do patrimônio público constituído dos recursos naturais, humanos e o direito de conviver e usufruir dos benefícios da sociedade em que atua.

\subsection{Relatórios Socioambientais}

As empresas que utilizam como matéria-prima os recursos naturais são passivas de constantes cobranças quanto à questão da sua responsabilidade socioambiental. Neste contexto, os relatórios socioambientais buscam evidenciar as melhores práticas e políticas voltadas para o meio ambiente e a sociedade.

Relatórios ambientais, socioambientais, ou simplesmente suplementos ambientais, são os meios que as empresas adotam para descrever e divulgar seu desempenho ambiental, compreendendo, de forma genérica, o fornecimento de dados auditados ou não, relativos aos eventos e impactos das atividades da empresa no meio ambiente e que envolvem, especificadamente, riscos, impactos, políticas, estratégias, alvos, custos, despesas, receitas, passivos ou qualquer outra informação relevante de seu desempenho ambiental, para todas aqueles que se interessa por esse tipo de informação, seus parceiros sociais, permitindo-os entender seu relacionamento com a empresa reportada (TINOCO; KRAEMER, 2004, P.257).

Para Barbieri (2007), decidir o que expor nos relatórios ambientais não é algo fácil depende de como seus dirigentes entendem a responsabilidade socioambiental e quais os objetivos a empresa quer alcançar. As informações apresentadas podem ser estruturadas através de modelos de relatórios próprios, padronizados, ou ainda fazer uma concomitância entre ambos, sejam eles, para atender as regulamentações normativas da legislação vigente, ter um maior controle de suas atividades ou ainda para demonstrá-los aos seus usuários e demais interessados. No entanto é importante que estas informações sejam verificáveis, compreensíveis e apresentadas com a formatação adequada para os usuários, conforme exposto no quadro 4 : 
Quadro 4 - Objetivos e conteúdos dos relatórios para usuários selecionados.

\begin{tabular}{|c|c|c|c|}
\hline Usuários & Objetivos do usuário & Objetivos da empresa & Conteúdo \\
\hline Academia & $\begin{array}{l}\text { Monitorar tendências, estabelecer e } \\
\text { publicar as melhores práticas }\end{array}$ & $\begin{array}{l}\text { Demonstrar voluntariamente uma } \\
\text { disposição de ser transparente nas suas } \\
\text { decisões relativas ao meio ambiente }\end{array}$ & $\begin{array}{l}\text { Política ambiental atual e futura. } \\
\text { Normas da empresa. } \\
\text { Detalhes do SGA. } \\
\begin{array}{l}\text { Desempenho relativo a objetivos e } \\
\text { metas específicos e definidos pela } \\
\text { empresa. }\end{array}\end{array}$ \\
\hline Empregados & $\begin{array}{l}\text { Conhecer as consequências } \\
\text { ambientais das operações } \\
\text { da empresa. }\end{array}$ & $\begin{array}{l}\text { Ampliar a comunicação entre os } \\
\text { empregados e a administração. } \\
\text { criar clima interno favorável à } \\
\text { participação de todos nos } \\
\text { programas e programas } \\
\text { ambientais }\end{array}$ & $\begin{array}{l}\text { Participação nas decisões. } \\
\text { Educação e programas de treinamentos. } \\
\text { Responsabilidade e conformidade } \\
\text { com os regulamentos. } \\
\text { Avaliação dos riscos. }\end{array}$ \\
\hline ONGs & $\begin{array}{l}\text { Saber dos esforços da empresa } \\
\text { relacionados com o conceito de } \\
\text { sustentabilidade e capacidade } \\
\text { de suporte da Terra. }\end{array}$ & $\begin{array}{l}\text { Demonstrar a responsabilidade social } \\
\text { informando como a empresa esta } \\
\text { contribuindo para reduzir os problemas } \\
\text { ambientais globais. }\end{array}$ & $\begin{array}{l}\text { Demonstração do cumprimento da } \\
\text { legislação ambiental. } \\
\text { Detalhes das tendências de } \\
\text { desempenho ambiental. } \\
\text { Informações sobre o ciclo de vida } \\
\text { dos produtos. }\end{array}$ \\
\hline $\begin{array}{l}\text { Comunidade } \\
\text { financeira e } \\
\text { acionista }\end{array}$ & $\begin{array}{l}\text { Saber a posição da empresa } \\
\text { quanto à legislação e } \\
\text { conhecer os padrões } \\
\text { ambientais atuais e iminentes } \\
\text { atuais e iminentes que afetam } \\
\text { os resultados da empresa. }\end{array}$ & $\begin{array}{l}\text { Demonstrar segurança quanto aos } \\
\text { riscos que podem elevar os passivos } \\
\text { da empresa e prejudicar a realização de } \\
\text { lucros futuros. }\end{array}$ & $\begin{array}{l}\text { Demonstração do cumprimento da } \\
\text { legislação ambiental. } \\
\text { Custos relacionados com as } \\
\text { atividades ambientais. } \\
\text { Considerações sobre as } \\
\text { metodologias de avaliação. } \\
\text { Passivos ambientais, contingências } \\
\text { e litígios. } \\
\text { Investimentos futuros. }\end{array}$ \\
\hline
\end{tabular}

Fonte: AZZONE G. et al, 1997 apud Barbieri, 2007, p. 259

\section{METODOLOGIA}

\section{I Tipo de Pesquisa}

A pesquisa bibliográfica, de natureza qualitativa, utilizou-se da tipologia adotada por Raupp e Beuren (2008). Trata-se de uma pesquisa de caráter descritivo uma vez que através de dados coletados do site da empresa, foram analisados se os relatórios socioambientais publicados auxiliam na elaboração do Balanço Social.

\subsection{Coleta e Tratamento dos Dados}

Para a coleta de dados adotou-se a compilação sobre as informações contidas nos relatórios socioambientais da empresa do seguimento de petróleo, localizada na cidade de Mossoró realizada em dezembro de 2011 através de relatórios 
disponíveis no site da organização estudada, que publica anualmente relatórios socioambientais.

A análise dos dados será descritiva, realizada a partir da análise nos relatórios da organização sobre as ações socioambientais e comparadas à luz da pesquisa científica, correlacionando-os ao estudo de forma a atender os objetivos da pesquisa.

\section{RESULTADOS E DISCUSSÕES}

A partir do estudo e do levantamento de informações sobre a contribuição dos relatórios socioambientais da referida empresa na elaboração do Balanço Social, se constata as melhores práticas e políticas voltadas para o meio ambiente e a sociedade, considerando os aspectos relacionados a seguir:

- Relatórios de responsabilidade socioambiental utilizados pela empresa

Através de análise nos relatórios da empresa analisada, a mesma utiliza relatórios de ações socioambientais, os quais devido ao compromisso da empresa com a excelência de sistemas de gestão pautados na ISO 14001, estes são publicados e contemplam informações que contemplam os aspectos de responsabilidade social, sustentabilidade, garantia da qualidade, saúde e segurança no trabalho dentre outras.

Sobre esses relatórios, Barbieri (2007), diz que: as informações apresentadas nos relatórios podem ser estruturadas através de modelos próprios, padronizados, ou ainda fazer uma concomitância entre ambos, sejam eles, para atender às regulamentações normativas da legislação vigente, ter um maior controle de suas atividades ou ainda para demonstrá-los aos seus usuários e demais interessados.

Portanto, percebe-se que a empresa analisada contribui com a perspectiva do objetivo específico em identificar se os tipos de relatórios que são gerados e publicados por essa empresa, evidenciam ações socioambientais da empresa, de forma a demonstrar e transparecer a preocupação da organização com o meio ambiente e com a sociedade, bem como agregar valor ao negócio.

- Indicadores dos relatórios socioambientais

Foram identificados indicadores de desempenho econômico, social e ambiental, entre outros indicadores padrões voltados para a diretoria da empresa, ou ainda para atender ao Sistema de
Gestão Integrado ISO 9001(Gestão de Qualidade) e ISO 14001 (Gestão Ambiental). As informações apresentadas são reforçadas através do pensamento de Tinoco (2002, pg.59), quando comenta que: "O Balanço Social é um instrumento de gestão e de informação que visa a evidenciar, da forma mais transparente possível, informações econômicas e sociais aos mais diferenciados usuários".

Estes indicadores medem os impactos que afetam a organização e as partes envolvidas no que se refere aos recursos investidos no âmbito econômico, social e ambiental.

- Usuários dos relatórios socioambientais Constatou-se que a empresa tem o compromisso de criar, desenvolver e manter relações com todas as partes interessadas, que seus relatórios são elaborados com o intuito de atender aos mais variados usuários, sejam eles, clientes internos, terceirizados, fornecedores, investidores, instituições financeiras, órgãos governamentais e a sociedade através de interação entre a empresa com universidades, escolas e empresas parceiras.

Os relatórios socioambientais contribuem para o desenvolvimento da empresa por apresentar em seu conteúdo, informações que elevam o nível de comprometimento com o social e o ambiental, tornando possível a análise por parte dos gestores de melhores práticas de desenvolvimento sustentável para a organização e todos que com ela interagem.

- Fatos geradores de Impactos ambientais causados pelo seguimento de petróleo

Identificou-se uma diversidade de fatores impactantes no processo da empresa em análise. De acordo com os dados coletados sobre sustentabilidade e preservação ambiental, a empresa provoca diversas alterações ao patrimônio ambiental para exploração de petróleo de gás, a partir da geração de resíduos sólidos, alteração no solo, emissões atmosféricas e geração de efluentes líquidos.

Coadunando com o exposto acima Ribeiro (2006) comenta que: as organizações ao exercerem suas atividades utilizam-se de recursos naturais, sejam eles, renováveis ou não. Essa utilização efetivada de forma inadequada afeta negativamente o patrimônio natural, acarretando a redução do volume de água potável, do nível de qualidade do ar e das terras produtivas, o que restringe, em longo prazo, as condições de vida da humanidade.

A consciência da organização em relação à utilização dos recursos naturais minimiza a responsabilidade sobre os efeitos causados em sua atividade e a faz diferenciar-se no setor que atua. 
- Compromisso em relação aos impactos ambientais

Diante do que foi analisado na política integrada da empresa, foi constatada uma preocupação em designar recursos voltados para a redução dos impactos causados por sua atividade, demonstrando sua preocupação e compromisso com a responsabilidade socioambiental quando: Investem em tecnologias não agressivas, treinamentos, qualificação de fornecedores e parceiros, pesquisas com foco no desenvolvimento sustentável e responsabilidade social. Tinoco (2008), afirma que a proteção ao meio ambiente vem se tornando uma preocupação cada vez mais frequente pelas empresas, por alguns formadores de opinião e por boa parte da população, em virtude das inúmeras agressões causadas pelo ser humano ao meio ambiente.

É importante que as empresas tornem-se cada vez mais inovadoras na forma como abordam os aspectos da utilização dos recursos naturais em suas atividades operacionais. Através de ações de preservação e conservação, ela evidencia em que nível se encontra o envolvimento da empresa em relação ao meio ambiente, uma vez que, existe uma cobrança maior por parte da sociedade no aperfeiçoamento das operações realizadas, a fim de reduzir os impactos causados pela mesma.

Em busca de cumprir com os novos desafios que afetam o desenvolvimento sustentável da organização, a aplicabilidade e o bom desempenho das políticas voltadas para a conscientização de sua responsabilidade social e ambiental, tende a contribuir de forma positiva para elevação do conceito da empresa no mercado que atua.

- Envolvimento da empresa com a comunidade

É perceptível a relação entre as informações constantes nos relatórios socioambientais da empresa em estudo com as informações contidas no Balanço Social quando Reis e Medeiros (2009) diz que, a responsabilidade social é assumida pelas organizações, quando aprimora suas relações de parceria, que envolve a participação em programas sociais, gerenciamento de meios para minimizar os impactos causados a comunidade, pelo desenvolvimento das operações, entre outras.

Destinar recursos voltados para ações sociais que possam ser legitimados pela comunidade sem discriminação, confirma sua visão de um futuro melhor e mais justo para àqueles que não passam de vítimas do processo produtivo.
Sendo possível verificar que os relatórios socioambientais da empresa estudada possuem informações suficientes que servem de insumos para a elaboração do Balanço Social.

\section{CONSIDERAÇÕES FINAIS}

Considerando que o balanço social é um demonstrativo das ações que as empresas fazem como intervenção no meio social com vista a fomentar o desenvolvimento nas áreas: econômicas, Sociais, tecnológicas e ambientais. Assim sendo, analisando a empresa no ramo de petróleo, constatou-se que esta contribui para alavancar o desenvolvimento socioambiental nas áreas acima citadas, através do compromisso em relação aos impactos ambientais com a realização de programas integrados de SMS - Saúde, Meio Ambiente e Segurança, programas de gerenciamento de resíduos, projetos socioculturais, recuperação de áreas degradadas, utilização de equipamentos antipoluentes, garantindo assim a manutenção da biodiversidade local e QVT - Qualidade de Vida no Trabalho dos seus colaboradores e parceiros terceirizados.

O objeto desse estudo teve a constatação evidente de que as ações de responsabilidade socioambientais desenvolvidas pela empresa que atua no ramo de petróleo poderão ser utilizadas para a elaboração do Balanço Social tanto no modelo GRI (Global Reporting Iniciative ou, no português, Iniciativa Global para Apresentação de Relatórios), como também no modelo IBASE, este modelo inclusive adotado e disponibilizado no site da corporação, concluiu-se que os objetivos correspondem ao esperado para uma empresa deste seguimento, de acordo com a pesquisa realizada, posto que foram constatadas as ações socioambientais inerentes aos tipos de informações necessárias para os modelos de Balanço Sociais, já citados.

A empresa apresenta em suas demonstrações a elaboração de um Balanço Social no modelo IBASE, e utiliza em seus relatórios de ações socioambientais, indicadores que apontam para esse fim, confirmando o objetivo proposto para essa pesquisa.

De acordo com as informações adquiridas pelo estudo dos modelos de Balanços Sociais: ETHOS, GRI E IBASE percebe-se, dados que favorecem a identificação dos modelos GRI e IBASE, como os mais viáveis, por transparecer as informações desenvolvidas pelas empresas do seguimento de petróleo, já que as ações registradas 
nos relatórios são compatíveis com as informações apresentadas no balanço social acima citado.

Esta pesquisa contribuiu positivamente através da identificação do modelo de Balanço Social, especificamente o IBASE adotado, pois o mesmo serve como uma ferramenta de prestação de contas entre a indústria e a sociedade, quando demonstra as ações realizadas em projetos sociais, aspectos humanos, econômicos e ambientais, voltados para a comunidade envolvida.

Percebe-se que a empresa mostra uma nova fase do capitalismo que está explorando uma vertente social como maneira de justificar o lucro obtido com a exploração do meio ambiente que socialmente pertence a todos.

\section{REFERÊNCIAS}

BARBIERI, José Carlos. Gestão Ambiental Empresarial: Conceitos, Modelos e Instrumentos. $2^{\circ}$ ed. Revista e atualizada. São Paulo: Saraiva, 2007.

CALIXTO, Laura. Vinte anos de discussão sobre o Balanço Social. Revista Brasileira de Contabilidade. Brasília, p. 23-35, set./out. 2005.

COMISSÃO DE VALORES MOBILIARIOS. Posição da CVM sobre o Balanço Social.

Disponível em: <http://www.cvm.gov.br/port/ public/publ/Publ 400.asp $>$ Acesso em: 05 maio 2011.

GLOBAL REPORTING INITIATIVE (GRI). Diretrizes para Relatórios de Sustentabilidade, 2006. Disponível em: $<$ http:// www. globalreporting.org.> Acesso 15 maio 2011.

INSTITUTO BRASILEIRO DE ANÁLISES SOCIAIS E ECONÔMICAS (IBASE). Balanço Social anual 2007. Disponível em: $<$ Erro! A referência de hiperlink não é válida. > Acesso em 05 maio 2011.

INSTITUTO ETHOS DE EMPRESAS E RESPONSABILIDADE SOCIAL. Guia de Elaboração do Balanço Social 2006. Disponível em: <http://www.balançosocial.org.br $>$ Acesso em 05 maio 2011.

KROETZ, César Eduardo Stevens. Balanço Social: uma proposta de normatização.
Revista Brasileira de Contabilidade. Brasília, p. 52-63, CFC, v. 30, nº 129 mai./jun. 2001.

PEROTTONI, Marco Antônio. Balanço Social: responsabilidade, padronização e obrigatoriedade Revista Brasileira de Contabilidade. Brasília, p. 50-59, mar./abr. 2002.

PINTO, Anacleto Laurindo; RIBEIRO, Maísa de Souza. Balanço social: Uma avaliação de informações fornecidas por empresas industriais situadas no estado de Santa Catarina.

Revista Contabilidade \& Finanças USP, São Paulo, ano XV, v. 4, n 36, p. 21-34, set./ dez. 2004.

RAUPP, Fabiano Maury; BEUREN, Ilse Maria. Metodologia de Pesquisa Aplicável às Ciências Sociais. In: BEUREN, Ilse Maria et al. Como elaborar trabalhos monográficos em contabilidade. 3. ed. São Paulo: Atlas, 2008. Cap. 3, p. 76-97.

REIS, Carlos Nelson dos; MEDEIROS, Luiz Edgar. Responsabilidade social das empresas e balanço social: meios propulsores do desenvolvimento econômico e social. 1. ed. 2. reimp. São Paulo: Atlas, 2009.

RIBEIRO, Maísa de Souza. Contabilidade ambiental. São Paulo: Saraiva, 2006.

SILVA, Benedito Albuquerque da. Contabilidade e meio ambiente: considerações teóricas e práticas sobre o controle dos gastos ambientais. São Paulo: Annablume/FAPESP, 2003.

TINOCO, João Eduardo Prudêncio; KRAEMER, Maria Elisabeth Pereira. Contabilidade e gestão ambiental. 2. ed. Atualizada de acordo com a Lei n. 11.638 de 28-12-2007 São Paulo: Atlas, 2008.

TINOCO, João Eduardo Prudêncio. Balanço social: uma abordagem da transparência e da responsabilidade pública das organizações. São Paulo: Atlas, 2008.

TINOCO, João Eduardo Prudêncio. Balanço social: balanço da transparência corporativa e da concertação social. Revista Brasileira de Contabilidade. Conselho Federal de Contabi- 
lidade. p. 57-73, maio/jun. de 2002.

TORRES, Ciro. Um pouco da história do

Balanço Social. Disponível em: $<$ balançosocial.org. br/cgi/cgilua.exe/sys/start.htm?infoi$\mathrm{d}=3 \&$ sid $=3>$. Acesso em: 05 maio 2011 .

http://www.petrobras.com.br/rs2010/pt/ relatorio-de-sustentabilidade/resultados-contribuicoes-sociedade/contribuicoes-sociedade -impactos-indiretos/avaliacao-de-impactos/>. Acesso em: 20 de dezembro 2011;

http://www.petrobras.com.br/rs2010/pt/ downloads/RS_2010.pdf $>$. Acesso em: 20 de dezembro $201 \overline{1}$. 